\title{
Feeding rates, assimilation efficiencies and growth of two amphipod species on biodeposited material from zebra mussels
}

\author{
RENÉ GERGS AND K.-O. ROTHHAUPT \\ Limnological Institute, University of Konstanz, Konstanz, Germany
}

\begin{abstract}
SUMMARY
1. Accumulation of organic material by the zebra mussel Dreissena polymorpha is assumed to be the source of a biodeposition-based food web. However, only little is known about the importance of the biodeposited material as a food source and its contribution to increased abundances of macroinvertebrates in the presence of D. polymorpha. 2. Feeding, assimilation and growth of the amphipods Gammarus roeselii and Dikerogammarus villosus on food sources directly and indirectly associated with $D$. polymorpha (biodeposited material and chironomids) and on conditioned alder leaves were measured. The stoichiometry of carbon, nitrogen and phosphorus of the diets was measured as an important determining factor of food quality.

3. Chironomids had the highest nitrogen and phosphorus contents, alder leaves were depleted in nitrogen and phosphorus, and the stoichiometry of biodeposited material was intermediate.

4. Both amphipod species had highest feeding rates and assimilation efficiencies on chironomids. Gammarus roeselii fed more on biodeposited material than on alder leaves, but assimilation efficiencies were similar; D. villosus also had similar feeding rates and assimilation efficiencies on the two diets.

5. Both amphipod species had highest growth rates on chironomids and lowest growth rates on alder leaves. Both grew at intermediate rates on biodeposited material of $D$. polymorpha. The growth rates of the amphipod species were related to food stoichiometry. Overall, the invasive $D$. villosus grew faster than the indigenous $G$. roeselii. 6. Food resources directly and indirectly associated with $D$. polymorpha are potential diets for amphipods, providing further evidence for a $D$. polymorpha biodeposition-based food web.
\end{abstract}

Keywords: Dikerogammarus villosus, feeding strategy, food quality, food web, Gammarus roeselii

\section{Introduction}

The growth and reproduction of many benthic macroinvertebrates depends on the quality and availability of potential food sources (Willoughby \& Sutcliffe, 1976; Fuller, Fry \& Roelofs, 1988; Söderström, 1988).

Correspondence: René Gergs, Limnological Institute, University of Konstanz, D-78464 Konstanz, Germany.

E-mail: rene.gergs@uni-konstanz.de
An important determining factor of food quality is the stoichiometry of carbon, nitrogen and phosphorus in the food (Frost et al., 2002). A stoichiometric mismatch between diet and consumer, caused by a low food quality, can lead to lower growth rates of the consumer even under a saturated food quantity (Frost \& Elser, 2002). A compensatory feeding response to low-nutrient food is possible but cannot fully compensate food quality-related deficiencies in growth (Fink \& von Elert, 2006). 
Allochthonous leaves are an important energy source in many streams, but are a low-quality food because of low phosphorus and nitrogen contents (Kaushik \& Hynes, 1971; Anderson \& Cummins, 1979; Friberg \& Jacobsen, 1994; Cross et al., 2005). Animal matter, in contrast, is a high-quality food source because of high phosphorus and nitrogen contents (Cross et al., 2005; Fink, Peters \& von Elert, 2006). Diet quality has often been estimated by assessing feeding rates and assimilation efficiencies (e.g. Bärlocher \& Kendrick, 1975; McCullough \& Minshall, 1979; Graca et al., 2001). However, these parameters cannot be related directly to growth and the estimation of growth rates is also important (Fuller et al., 1988).

In many freshwater systems in Europe and North America, the littoral habitat and benthic energy flow have been modified by the invasion of the zebra mussel, Dreissena polymorpha (Pallas). Following the arrival of zebra mussels, the abundance of many benthic taxa, especially amphipods and chironomids, increases (Stewart \& Haynes, 1994; Stewart, Miner \& Lowe, 1998; Mörtl \& Rothhaupt, 2003). Zebra mussels alter the benthic habitat by increasing surface area and restructuring the substrate in the form of mussel shells. The mussels influenced the benthic community also by biodeposition, the excretion of faeces and pseudofaeces. This causes an accumulation of pelagic resources in the benthos (Stanczykowska et al., 1976; Klerks, Fraleigh \& Lawniczak, 1996; Silver Botts, Patterson \& Schloesser, 1996; Ricciardi, Whoriskey \& Rasmussen, 1997). It is assumed that the availability of this new food resource leads to a biodeposition-based food web (Stewart \& Haynes, 1994; Mitchell et al., 1996). The amphipods may benefit from the new resource directly by feeding on the biodeposited matter or indirectly by feeding on associated invertebrates (i.e. those that feed on the matter, such as chironomids). Gammarids are often classified as shredders, but it is usually not possible to classify them into a discrete functional feeding group because their feeding strategy has great plasticity (MacNeil, Dick \& Elwood, 1997). Hence, gammarid amphipods are best characterized as omnivores (Bärlocher \& Kendrick, 1973; Pöckl, 1992).

Recent laboratory experiments have shown that the biodeposited material of zebra mussels is a food source and affects habitat choice of the native amphipod Gammarus roeselii Gervais, whereas the invasive amphipod Dikerogammarus villosus (Sowinsky), a predator (Dick \& Platvoet, 2000; Dick, Platvoet \& Kelly, 2002), is not attracted by biodeposited material but rather by the associated chironomids (Gergs \& Rothhaupt, 2008). Although gammarid amphipods and chironomids can grow on faeces and pseudofaeces of zebra mussels (Izvekova \& Lvova-Katchanova, 1972; González \& Burkart, 2004), little is known about the quality and utilization of the biodeposited material as food. Since biodeposited matter and chironomids might be important in habitats dominated by zebra mussels, we investigated the feeding, assimilation and growth of $G$. roeselii and D. villosus on these resources. We also compared these food sources to allochthonously introduced leaves, which are an important energy source in many aquatic systems (Minshall, 1967; Kaushik \& Hynes, 1971; Webster \& Benfield, 1986) and a better food source for gammarid amphipods than decaying macrophytes or green algae (Pöckl, 1995).

\section{Methods}

\section{Test animals: origin and maintenance}

The experiments were conducted with the two dominant amphipod species of Lake Constance, the indigenous $G$. roeselii and the invasive $D$. villosus. The species were obtained from the littoral of Lake Constance and kept separate in a $15^{\circ} \mathrm{C}$ climate chamber with a diurnal light rhythm of $12 \mathrm{~h}: 12 \mathrm{~h}$ (day :night). Gammarus roeselii was maintained in tanks filled with water from Lake Constance. Dikerogammarus villosus was kept in a flow-through system with water from Lake Constance to minimize their mortality rate. Both were fed on commercially available frozen chironomids. For shelter, a mixture of gravels of different grain sizes was provided. In the experiments, amphipods of both sexes were used randomly.

\section{Food types}

Three different food sources were tested: dead animal material (commercially available frozen chironomids), material biodeposited by zebra mussels (D. polymorpha) and conditioned alder leaves.

To estimate the quantity of chironomids at the beginning of the feeding experiments, a length-ashfree dry mass correlation was established. The chironomids were measured with a digital sliding calliper (Preisser; Digi-Met, Gammertingen, Germany) to the nearest $0.01 \mathrm{~mm}$, and the ash-free dry mass was 
determined by drying the chironomids at $105^{\circ} \mathrm{C}$ for $24 \mathrm{~h}$, weighing, combusting at $550{ }^{\circ} \mathrm{C}$ for $8 \mathrm{~h}$ and weighing again for ash content.

Biodeposited material was collected in the lake using modified sediment traps consisting of a tube of grey PVC $(50 \mathrm{~cm}$ length; $\varnothing 10 \mathrm{~cm})$ to which a funnel and a 200-mL PET flask were fixed at the lower end to collect the settling sediment. A clamp was used to hold two tiles $(4.7 \times 4.7 \mathrm{~cm})$ with 15 living mussels $(15.01 \pm 0.40 \mathrm{~mm}$ shell length) each in a vertical position above the upper opening of the sediment trap. The mussels were collected from the littoral of Lake Constance. Five traps were suspended at a depth of $2 \mathrm{~m}$ from a pontoon in the pelagic zone of Lake Constance for 7 days. The collected material was centrifuged (1180 $\mathrm{g}, 6 \mathrm{~min}$ ), and the supernatant was replaced with enough distilled water to bring the volume to $100 \mathrm{~mL}$. Biodeposited material was stored at $4{ }^{\circ} \mathrm{C}$ in darkness. An aliquot was filtered on pre-combusted glass fibre filters $(\mathrm{GF} / 6, \varnothing 25 \mathrm{~mm}$; Whatman/Schleicher \& Schuell, Kent, U.K.), and the ash-free dry mass was determined to estimate the appropriate amount for the experiments.

The alder leaves were conditioned by exposing them for 3 weeks in the littoral of Lake Constance in $200-\mu \mathrm{m}$ litterbags to exclude macroinvertebrates. From a sub-sample of 16 leaf discs (diameter $1 \mathrm{~cm}$ ), the ash-free dry mass was determined to estimate the appropriate amount for the experiments.

The organic carbon, nitrogen and phosphorus content of the three food sources were estimated to assess food quality. Aliquots of the biodeposited material were filtered on pre-combusted glass fibre filters (GF/6, Ø $25 \mathrm{~mm}$; Whatman/Schleicher \& Schuell). Sub-samples of the conditioned alder leaves and the chironomids were ground. The samples were dried at $55{ }^{\circ} \mathrm{C}$ for subsequent analysis of particulate organic carbon and particulate organic nitrogen with an NCS-2500 analyser (Carlo Erba Instruments, Milano, Italy). For determination of particulate phosphorus, aliquots of the biodeposited matter were filtered through acid-rinsed polysulfone membrane filters ( $0.2 \mu \mathrm{m}$ pore size, $\varnothing 45 \mathrm{~mm}$; HT-200, Pall, Ann Arbor, MI, U.S.A.). For the conditioned alder leaves and the chironomids, sub-samples as described above were used. The samples were digested with a solution of $10 \%$ potassium peroxodisulfate and $1.5 \%$ sodium hydroxide at $121{ }^{\circ} \mathrm{C}$ for $60 \mathrm{~min}$, and soluble reactive phosphorus was then determined using the molybdate-ascorbic acid method (Greenberg, Trussel \& Clesceri, 1985). Both analyses were replicated five times for each food type.

\section{Feeding rates and assimilation efficiencies}

To estimate feeding rates and assimilation efficiencies, single adult test animals ( $>10 \mathrm{~mm}$ body length) were fed a specific amount of a single food source. All food sources were provided in saturated quantity. Chironomid replicates each received seven chironomids (5.2 $\pm 0.4 \mathrm{mg}$ ash-free dry mass), alder leaf replicates received one leaf disc $(4.8 \pm 1.0 \mathrm{mg}$ ash-free dry mass) and biodeposition replicates received an aliquot of $4.8 \pm 0.1 \mathrm{mg}$ ash-free dry mass.

The weight-specific feeding rate was determined as food ingested per day, being the difference between the ash-free dry mass of offered and remaining food per unit weight (ash-free dry mass) of animal. The assimilation efficiency was calculated as the percentage ratio between assimilated (ingested food - faeces) and ingested food.

The experiments were arranged in containers $(10.5 \times 10.5 \times 3.5 \mathrm{~cm})$ filled with $0.3 \mathrm{~L}$ of aerated lake water that had been filtered through a $0.45-\mu \mathrm{m}$ filter to eliminate potential food for the amphipods. A stone approximately $2 \mathrm{~cm}$ in diameter was provided as a shelter. All amphipods used in the experiments were pre-fed on the tested food source for $24 \mathrm{~h}$ and prestarved for another $24 \mathrm{~h}$ individually. After $24 \mathrm{~h}$ of feeding on the tested food source the remaining food and the faeces were collected separately. Faeces particles were identifiable easily by cylindrical pellets. Subsequent the feeding period, each individual was starved for $24 \mathrm{~h}$ to collect faeces. The accumulated faeces produced during the feeding and the postexperimental starving time was pooled for each individual. In every $24-h$ period described above a new container with new water was provided. For both starving periods, individuals were placed in a PVC cylinder (Ø $6 \mathrm{~cm}$; $8 \mathrm{~cm}$ height) with a 1-mm gauze $0.5 \mathrm{~cm}$ above the ground, installed in a container filled with lake water. Since amphipods do not empty their gut completely (Bärlocher \& Kendrick, 1975), the prefeeding and pre-starving were integrated into the experiment. We assumed that gut fullness at the start of the experiment equals gut fullness at the end of the starving period when faeces are collected. After $24 \mathrm{~h}$ of feeding, the remaining food of each replicate and 
the ash-free dry mass were determined. All faeces of each replicate were filtered on pre-combusted glass fibre filters (GF/6, Ø $25 \mathrm{~mm}$; Whatman/Schleicher \& Schuell) and their weight determined. All experiments were conducted in April and May 2007. Each diet was replicated 15-16 times, depending on survival of the amphipods. Sixteen additional replicates of each food source without amphipods were installed as controls to estimate the weight decline of food during the experimental period.

\section{Growth experiment}

During the growth experiment, all amphipods (juveniles, c. $5 \mathrm{~mm}$ body length at the beginning of the experiment) were kept individually in $100-\mathrm{mL}$ widenecked flasks. Each flask was filled with $90 \mathrm{~mL}$ lake water $\left(30-\mu \mathrm{m}\right.$ filtered, held at $\left.17^{\circ} \mathrm{C}\right)$ with a flowthrough of approximately $6 \mathrm{~mL} \mathrm{~min}{ }^{-1}$. The outflow passed through a 1-mm net to avoid drift of animals. The same food sources as in the feeding experiments were offered ad libitum. Additionally, individuals of both species were kept without food as controls. The growth experiment lasted 8 weeks from June to August 2007. All food tests and controls were replicated 10 times for each species. Flasks were cleaned, new food was added and the survival of the amphipods was noted weekly. Body length, the distance between the anterior of the head and the posterior of the final abdominal segment (Baumgärtner \& Rothhaupt, 2003), was measured at the beginning of the experiment and then every 2 weeks. Length was determined from photographs taken under a stereomicroscope (Zeiss Stemi 2000-C, Jena, Germany) with an attached fire-wire camera (Imaging Source, Bremen, Germany) connected to a computer. Each amphipod was measured three times using a computer program developed by the electronics facility of the University of Konstanz (G. Heine, pers. comm..). The mean value of the three measurements was used for further analyses.

\section{Statistical analysis}

All statistical analyses were made using the statistical package sPSS (version 15.0/2006; SPSS Inc., Chicago, IL, U.S.A.).

Weight-specific feeding rates were calculated as the dry weight of food ingested per animal body mass and day. To homogenize variances, all values were logarithmically transformed $[\ln (x+1)]$ and checked with the Levene test. Assimilation efficiency was calculated if the feeding rate was $>0.05 \mathrm{mg}$ food (mg amphipod $)^{-1}$ day $^{-1}$. At lower feeding rates, the systematic error in the determination of faeces and ingested food was a limiting factor. It was not necessary to transform the assimilation efficiency data to homogenize variances; the values were checked directly with the Levene test. Intraspecific differences between the food sources were analysed using a oneway ANOVA with subsequent Scheffe post hoc tests for unequal number of replicates. Interspecific differences between G. roeselii and D. villosus were evaluated using a two-way ANOvA to test for food and species effects. The $\mathrm{C}: \mathrm{P}$ and the $\mathrm{C}: \mathrm{N}$ ratios were the factors used to determine food quality. Differences in stoichiometry were analysed using a one-way ANOVA with subsequent Tukey-HSD post hoc test.

To analyse time effects on body lengths measured in the growth experiment, two-way ANOVAs with the factors time and food for both amphipod species were conducted. The control treatment without food was excluded from the analyses because of the high mortality of both species. We calculated weekly growth rates [body length (week $n)_{\text {-body length }}$ (week $n-2) / 2$ ] for each food and species using amphipods that survived until the following measurement. Intraspecific differences in food resources were analysed using a repeated-measures ANOVA with subsequent Scheffe post hoc tests for unequal numbers of replicates. Interspecific differences between G. roeselii and $D$. villosus were evaluated using a two-way ANOva to test for food and species effects. For all ANOvAs, all values were logarithmically transformed $[\ln (x+1)]$ and homogeneity of variances was checked with the Levene test. Survival of the amphipods was recorded weekly and analysed using a nonparametric GehanWilcoxon test for estimating survival distribution (Pyke \& Thompson, 1986).We tested for intraspecific differences among food tests and interspecific differences within each food test.

\section{Results}

Food stoichiometry

The organic carbon, nitrogen and phosphorus stoichiometry ( $\mathrm{C}: \mathrm{N}$ and $\mathrm{C}: \mathrm{P}$ ratios) of the three food 

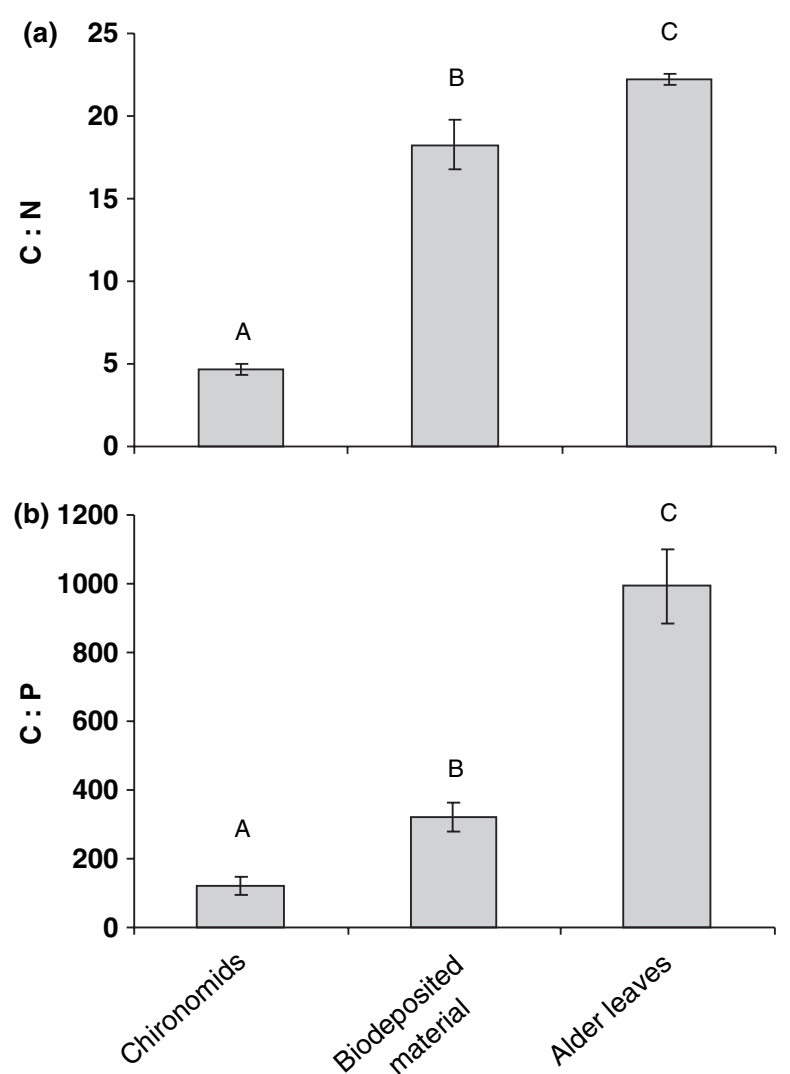

Fig. 1 Organic carbon, nitrogen and phosphorus stoichiometry of the three tested food sources, as indicated by (a) the C : N ratio and (b) the $C: P$ ratio. Mean values \pm SD are shown. Capital letters indicate homogenous subgroups detected by ANOVA with subsequent Tukey-HSD post hoc tests.

sources differed significantly (Fig. 1; ANOVA; $P<0.001)$. Chironomids had the highest nitrogen content, as indicated by a low $\mathrm{C}: \mathrm{N}$ ratio of approximately 5 . The biodeposited material of zebra mussels contained less nitrogen ( $\mathrm{C}: \mathrm{N}$ ratio of 18), and conditioned alder leaves had the lowest nitrogen content ( $\mathrm{C}: \mathrm{N}$ ratio of 22). Chironomids also had the highest phosphorus content ( $\mathrm{C}: \mathrm{P}$ ratio of 120$)$. The biodeposited material of zebra mussels contained less phosphorus ( $\mathrm{C}: \mathrm{P}$ ratio of 320 ), and conditioned alder leaves were severely depleted in phosphorus $(\mathrm{C}: \mathrm{P}$ ratio of nearly 1000).

\section{Feeding rates and assimilation efficiencies}

The weight-specific feeding rates of $G$. roeselii on the three food sources differed significantly (ANOVA; $P<0.001$; Table 1). Chironomids resulted in the highest feeding rates; the feeding rates on biodeposited
Table 1 ANOVA results comparing feeding rates, assimilation efficiency and growth rates of the 2 amphipod species, Gammarus roeselii and Dikerogammarus villosus

\begin{tabular}{|c|c|c|c|c|c|}
\hline Factor & Species & Effect & $F$ & d.f. & $P$-value \\
\hline \multirow[t]{5}{*}{ Feeding rate } & G. roeselii & Diet & 43.8 & 2 & $<0.001$ \\
\hline & D. villosus & Diet & 11.2 & 2 & $<0.001$ \\
\hline & Both & Species & 26.6 & 1 & $<0.001$ \\
\hline & & Diet & 51.0 & 2 & $<0.001$ \\
\hline & & Species $\times$ diet & 7.4 & 2 & 0.001 \\
\hline \multirow{5}{*}{$\begin{array}{l}\text { Assimilation } \\
\text { efficiency }\end{array}$} & G. roeselii & Diet & 30.8 & 2 & $<0.001$ \\
\hline & D. villosus & Diet & 10.4 & 2 & $<0.001$ \\
\hline & Both & Species & 0.2 & 1 & 0.69 \\
\hline & & Diet & 32.0 & 2 & $<0.001$ \\
\hline & & Species $\times$ diet & 0.1 & 2 & 0.87 \\
\hline \multirow[t]{5}{*}{ Growth rate } & G. roeselii & Diet & 5.0 & 2 & 0.03 \\
\hline & D. villosus & Diet & 61.2 & 2 & $<0.001$ \\
\hline & Both & Species & 15.2 & 1 & $<0.001$ \\
\hline & & Diet & 41.8 & 2 & $<0.001$ \\
\hline & & Species $\times$ diet & 8.3 & 2 & 0.001 \\
\hline
\end{tabular}

The differences between the three food types, chironomids, material biodeposited by zebra mussels (D. polymorpha) and conditioned alder leaves were analysed.

material of $D$. polymorpha were intermediate and lowest on conditioned alder (Fig. 2a). The feeding rate of $D$. villosus was also highest on chironomids, and the rates on the other two food sources were lower, respectively (ANOVA; $P<0.001$ ). The interspecific comparison showed significant differences between the feeding rates of the amphipod species (ANOVA; $P<$ 0.001; Table 1) and significant species $\times$ diet interactions (ANOVA; $P=0.001$ ). The weight-specific feeding rate of $G$. roeselii on chironomids was two-fold higher than that of $D$. villosus and three-fold higher on biodeposited material. The feeding rates of the two amphipod species on conditioned alder leaves did not differ.

The assimilation efficiencies of the two amphipod species did not differ (ANOVA; $P=0.69$; Table 1 ) and no significant species $\times$ diet interactions (ANOVA; $P=0.87$ ) were found. However, assimilation efficiencies on the food sources differed for $G$. roeselii and $D$. villosus (ANOvA; both species: $P<0.001$ ). Assimilation efficiency was highest with chironomids as the food source (c. 70\%) and lowest on biodeposited material of $D$. polymorpha and conditioned alder leaves (c. 40\% each; Fig. 2b).

\section{Growth experiment}

Both species increased in body length during the 8-week experiment on all food sources (Fig. 3; ANOVA; 

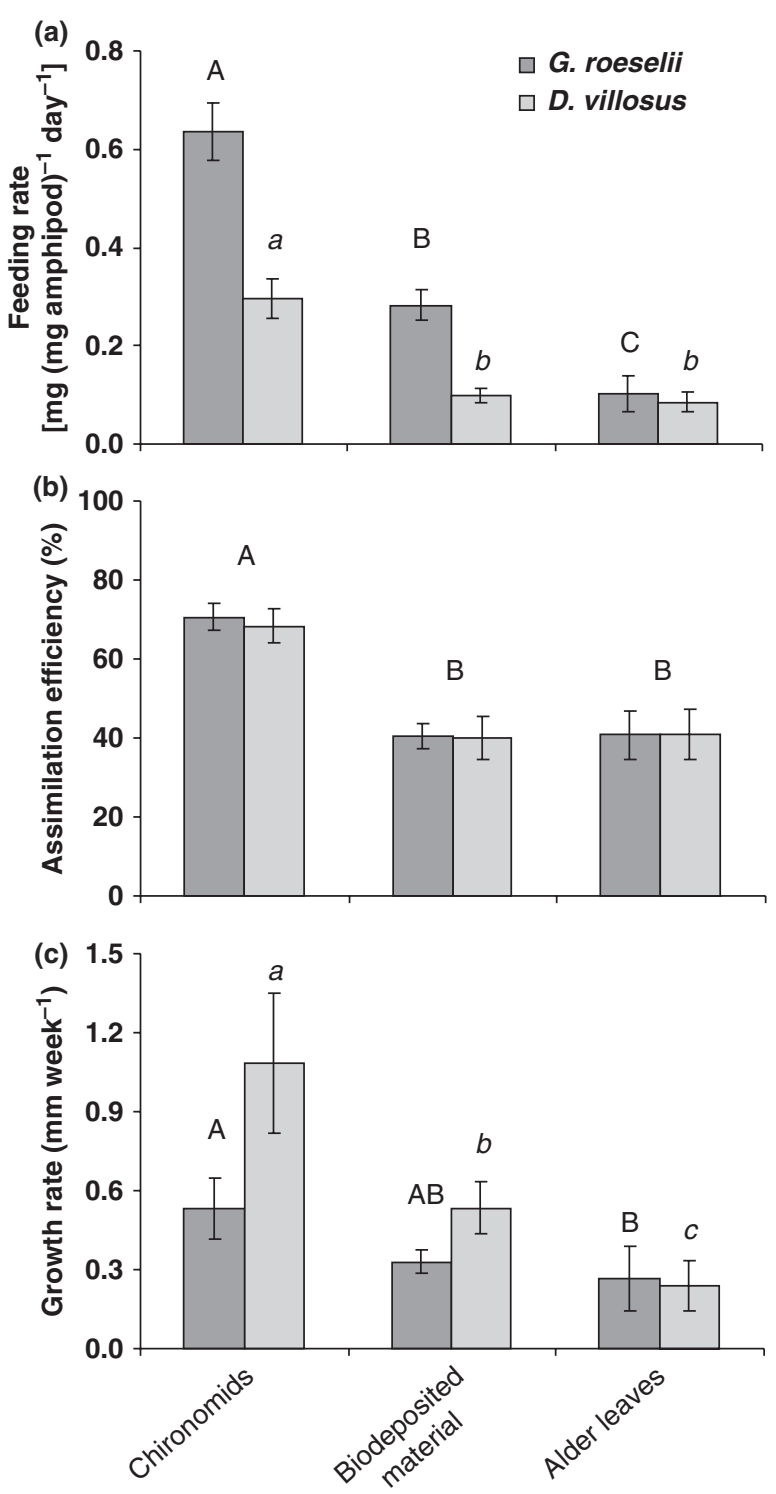

Fig. 2 (a) Feeding rate, (b) assimilation efficiency and (c) growth rate of the amphipod species Gammarus roeselii and Dikerogammarus villosus on three different food sources: chironomids, biodeposited material of zebra mussels, and conditioned alder leaves. Mean values \pm SD are shown. In (a) and (c), upper case letters indicate homogenous subgroups for $G$. roeselii and lower case letters indicate homogenous subgroups for $D$. villosus, as detected by the ANOVA with subsequent Scheffe post hoc tests for unequal number of replicates. In (b), no significant differences were found between species and the upper case letters indicate homogenous subgroups for both species.

both species: $P<0.001$; Table 2). Growth differed on the different food source (ANOVA; both species: $P<0.001)$ and significant diet $\times$ time interactions were found (ANOVA; both species: $P<0.001$ ). The body length of G. roeselii and D. villosus increased the

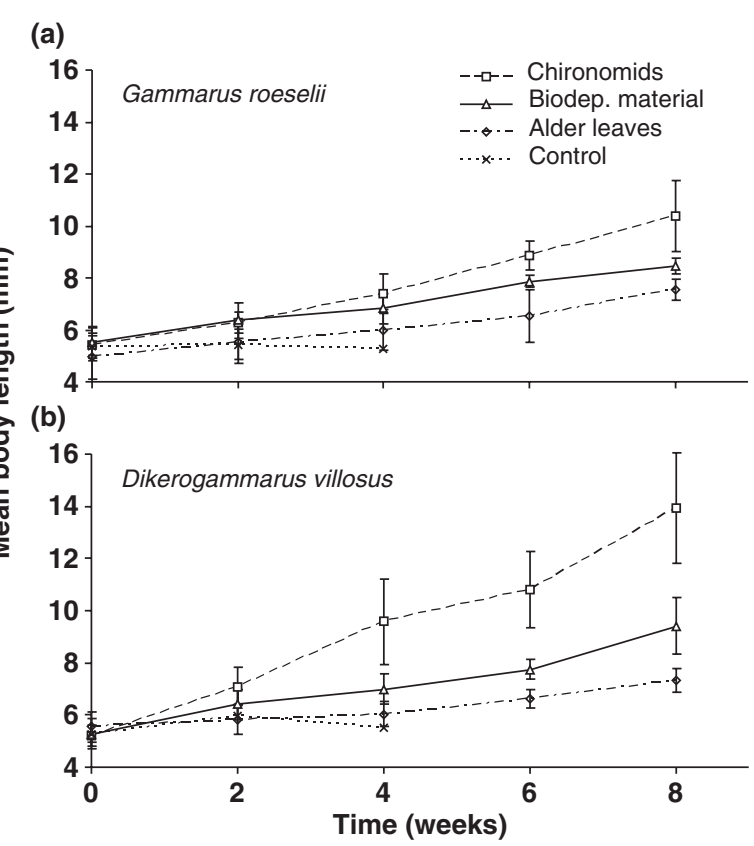

Fig. 3 Body length (mean \pm SD) of (a) Gammarus roeselii and (b) Dikerogammarus villosus fed chironomids, biodeposited material of zebra mussels, and conditioned alder leaves for 8 weeks and in the control without food.

Table 2 ANOVA results comparing increase in mean body length of the 2 amphipod species, Gammarus roeselii and Dikerogammarus villosus for the duration of the growth experiment of 8 weeks

\begin{tabular}{lllll}
\hline Species & Effect & $F$ & d.f. & $P$-value \\
\hline G. roeselii & Time & 29.8 & 4 & $<0.001$ \\
& Diet & 23.9 & 2 & $<0.001$ \\
& Diet $\times$ time & 14.1 & 8 & $<0.001$ \\
D. villosus & Time & 17.2 & 4 & $<0.001$ \\
& Diet & 62.1 & 2 & $<0.001$ \\
& Diet $\times$ time & 30.0 & 8 & $<0.001$ \\
\hline
\end{tabular}

Differences depending on time and the three food source chironomids, material biodeposited by zebra mussels (D. polymor$p h a)$ and conditioned alder leaves were analysed.

most when fed chironomids, followed by biodeposited material of $D$. polymorpha. The increase in body length was lowest when both species fed conditioned alder leaves.

Growth rates of both amphipod species on the different food sources differed significantly (Fig. 2c; repeated-measures ANOVA; $G$. roeselii: $P=0.03$; D. villosus: $P<0.001$; Table 1$)$. The growth rate of G. roeselii fed chironomids twice as high as G. roeselii fed conditioned alder leaves; growth of G. roeselii fed 
biodeposited material was intermediate. The growth rate of $D$. villosus fed chironomids was twice and triply higher than $D$. villosus fed biodeposited material and conditioned alder leaves respectively. The growth of the two species differed (ANOVA; $P<0.001$ ), and there were significant species $\times$ diet interactions (ANOva; $P=0.001$ ). Dikerogammarus villosus fed chironomids and biodeposited material had higher growth than G. roeselii fed on the same diets respectively. The growth rates of the two species fed conditioned alder leaves did not differ.

The survival of the two species on the different food sources also differed (G. roeselii: Wilcoxon-Gehan statistic $=42.19, \quad P<0.001 ; \quad D$. villosus: WilcoxonGehan statistic $=121.88, P<0.001)$. In the controls lacking food, survival of both species was significantly lower than when food was available (Fig. 4). Survival of both $G$. roeselii and D. villosus was highest when fed conditioned alder leaves. Survival of G. roeselii fed chironomids and biodeposited material was lower. For $D$. villosus the same order in survival as described for $G$. roeselii occurred among the three diets. Survival of the two species in the controls lacking food did not differ (Wilcoxon-Gehan statistic $=0.02, P=0.897$ ).

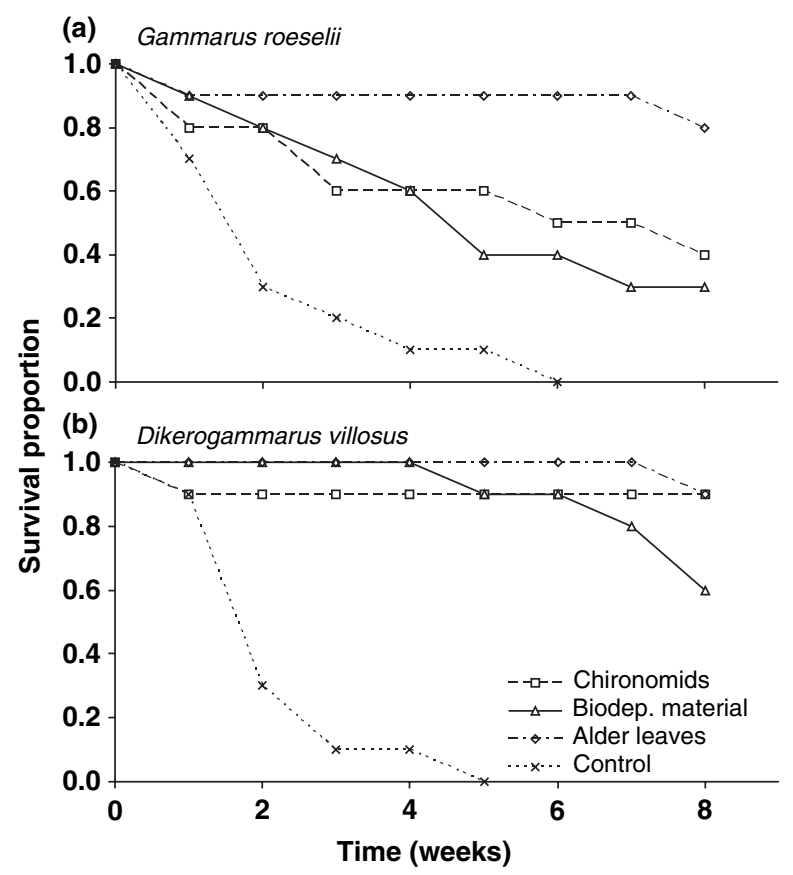

Fig. 4 Survival of (a) Gammarus roeselii and (b) Dikerogammarus villosus fed chironomids, biodeposited material of zebra mussels, and conditioned alder leaves for 8 weeks and in the control without food.
The survival of $D$. villosus on all three food sources was higher than that of $G$. roeselii (chironomids: Wilcoxon-Gehan statistic $=9.31, P=0.002$; biodeposited material: Wilcoxon-Gehan statistic $=21.01$, $P<0.001$; conditioned alder leaves: Wilcoxon-Gehan statistic $=6.32, P=0.012$ ).

\section{Discussion}

The growth and feeding of the amphipod species $G$. roeselii and $D$. villosus differed on the three food sources offered in our experiments. In general, however, both amphipod species responded according to the nutritional gradient proposed by Anderson \& Cummins (1979), with animal material as a highquality food and leaf litter as a low-quality food. The animal material food source, chironomids, led to the highest feeding rates and assimilation efficiencies of both amphipod species, resulting in high growth rates. The high nitrogen and phosphorus contents of the chironomids food source also indicate its high food quality. Similar C : N and C : P ratios have been found for G. roeselii in Lake Constance (Fink et al., 2006). The leaf litter food source, conditioned alder leaves, had the lowest food quality, and the quality of biodeposited material of zebra mussels as a food source was intermediate between that of the animal material and the leaf litter.

Gammarus roeselii fed at a higher rate on higher quality food sources, which resulted in faster growth. Gammarus roeselii had higher feeding rates than D. villosus on chironomids and biodeposited material at similar assimilation efficiencies. This implies a higher assimilated food biomass per animal biomass for $G$. roeselii. However, the growth rate of $D$. villosus was higher, which indicated that energy allocation differed between the two amphipod species. Since the native amphipod G. roeselii has a higher activity than the invasive D. villosus (Kinzler \& Maier, 2006), $G$. roeselii probably requires a larger proportion of available energy for motility, whereas $D$. villosus possibly allocates more energy to somatic growth. The growth rate of $D$. villosus fed chironomids in our experiments corresponds well with the calculated field growth rates in spring and summer of Piscart et al. (2003). Compared to indigenous amphipod species, the invader $D$. villosus has rapid growth, a bigger brood size, earlier sexual maturity and a shorter egg development time (Piscart et al., 2003; Pöckl, 2007). 
These ecological traits are important for successful invasion (Ricciardi \& Rasmussen, 1998; Kolar \& Lodge, 2001).

The preference of gammarid amphipods for various leaf litters and the role of aquatic fungi on leaves have been well investigated (e.g. Bärlocher \& Kendrick, 1973), but the predatory impact of gammarids has often been neglected until recently (Kelly, Dick \& Montgomery, 2002). In contrast to G. roeselii, the invader D. villosus is clearly a predator (Dick \& Platvoet, 2000; Dick et al., 2002), which may also explain its high growth rate on chironomids in our experiments. Although the feeding rates and assimilation efficiencies of $D$. villosus on biodeposited material of zebra mussels and conditioned alder leaves did not differ, the amphipods grew better on the biodeposited material. The higher growth rate on this food source may be attributed to the higher phosphorus content, which can enhance growth under limiting conditions (Frost \& Elser, 2002; Frost, Cross \& Benstead, 2005).

Food constituents can be assimilated with different efficiencies, and consumers limited by nutrients ( $\mathrm{N}$ or P) have been shown to assimilate the limiting element with a higher efficiency than carbon (Rothhaupt, 1995; Sterner \& Elser, 2002). Gross growth efficiencies and hence assimilation efficiencies can be close to $100 \%$ for elements that are deficient in the food (Sterner \& Elser, 2002). In our experiments, the $C: P$ ratio of biodeposited material was $320: 1$, whereas that of alder leaves was about $1000: 1$. If we assume that the assimilation efficiencies that we determined for both food types (c. $40 \%$ ) reflect the assimilation of carbon and that the deficient element phosphorus was assimilated with a high efficiency of $90 \%$, the resulting assimilated $\mathrm{C}: \mathrm{P}$ ratios would be $140: 1$ for the biodeposited material and $440: 1$ for the alder leaves. A C : P ration of $140: 1$ is close to the body stoichiometry of Gammarus (Fink et al., 2006).

In the control lacking food, the survival of both amphipod species was lowest; only a few individuals survived after 3 weeks. The flow through of lake water in the flasks did not contain enough food for growth or survival of the amphipods. Hence, all growth effects observed in our experiments can be attributed to the offered food sources.

Both amphipod species had the highest survival and the lowest growth rate on conditioned alder leaves. This apparent paradox can be explained as follows. Individual growth of crustaceans requires moulting, and animals may be less resistant to toxicants in the post-moult stage, caused by high metabolic stress and the not yet hardened exoskeleton (Carlisle \& Knowles, 1959). The intermoult interval increases with decreasing growth rates caused by lower food quality (Willoughby \& Sutcliffe, 1976; Pöckl, 1995). Therefore, at lower growth rates, fewer individuals are in the vulnerable moulting phase, and survival should increase, as we observed.

Our results indicate that biodeposited material of the zebra mussel $D$. polymorpha is a potential intermediate-quality food source for both $G$. roeselii and D. villosus. In line with this result, González \& Burkart (2004) found that mussel faeces and pseudofaeces were a valuable food source for Gammarus fasciatus Say. These findings support the assumption of a biodeposition-based food web originating from food sources provided by the zebra mussel (Stewart \& Haynes, 1994; Mitchell et al., 1996). Furthermore, chironomids feed well on this food source (Izvekova \& Lvova-Katchanova, 1972). Hence, predators such as $D$. villosus can benefit indirectly from the biodeposition of the zebra mussel by predation on macroinvertebrates. Thus, the increase in abundance of many benthic taxa after the invasion of $D$. polymorpha might to some extent be an effect of increased food availability. However, the significance the accumulation of organic matter by zebra mussels under natural conditions remains unknown although stable isotope analyses have indicated that this food source constitutes a part of the diet of the amphipod G. fasciatus (Limén, van Overdijk \& MacIsaac, 2005). Our results on the feeding and growth of the two amphipods $G$. roeselii and $D$. villosus on resources associated with zebra mussels provide further evidence for the importance of zebra mussel biodeposited material under natural conditions.

\section{Acknowledgments}

The authors thank André Gergs and Almut Hanselmann for their comments on an earlier version of the manuscript and Karen A. Brune for editing the English language of the manuscript. Thanks are also due to Christoph Berron for ideas on the experimental setup. This work was supported by the DFG (German Research Foundation) within the collaborative research centre SFB 454 'Littoral of Lake Constance'. 


\section{References}

Anderson N.H. \& Cummins K.W. (1979) Influences of diet on the life history of aquatic insects. Journal of the Fisheries Research Board of Canada, 36, 335-342.

Bärlocher F. \& Kendrick B. (1973) Fungi and food preferences of Gammarus pseudolimnaeus. Archiv für Hydrobiologie, 72, 501-516.

Bärlocher F. \& Kendrick B. (1975) Assimilation efficiency of Gammarus pseudolimnaeus (Amphipoda) feeding on fungal mycelium or autumn-shed leaves. Oikos, 26, 5559.

Baumgärtner D. \& Rothhaupt K.O. (2003) Predictive length-dry mass regressions for freshwater invertebrates in a pre-alpine lake littoral. International Review of Hydrobiology, 88, 453-463.

Carlisle D.B. \& Knowles F. (1959) Endocrine Control in Crustaceans. University Press, Cambridge.

Cross W.F., Benstead J.P., Frost P.C. \& Thomas S.A. (2005) Ecological stoichiometry in freshwater benthic systems: recent progress and perspectives. Freshwater Biology, 50, 1895-1912.

Dick J.T.A. \& Platvoet D. (2000) Invading predatory crustacean Dikerogammarus villosus eliminates both native and exotic species. Proceedings of the Royal Society of London, Series B, 267, 977-983.

Dick J.T.A., Platvoet D. \& Kelly D.W. (2002) Predatory impact of the freshwater invader Dikerogammarus villosus (Crustacea: Amphipoda). Canadian Journal of Fisheries and Aquatic Sciences, 59, 1078-1084.

Fink P. \& von Elert E. (2006) Physiological responses to stoichiometric constraints: nutrient limitation and compensatory feeding in a freshwater snail. Oikos, 115, 484-494.

Fink P., Peters L. \& von Elert E. (2006) Stoichiometric mismatch between littoral invertebrates and their periphyton food. Archiv für Hydrobiologie, 165, 145165.

Friberg N. \& Jacobsen D. (1994) Feeding plasticity of two detritivore-shredders. Freshwater Biology, 32, 133-142.

Frost P.C. \& Elser J.J. (2002) Growth response of littoral mayflies to the phosphorus content of their food. Ecology Letters, 5, 232-240.

Frost P.C., Stelzer R.S., Lamberti G.A. \& Elser J.J. (2002) Ecological stoichiometry of trophic interactions in the benthos: understanding the role of C:N:P ratios in lentic and lotic habitats. Journal of the North American Benthological Society, 21, 515-528.

Frost P.C., Cross W.F. \& Benstead J.P. (2005) Ecological stoichiometry in freshwater benthic ecosystems: an introduction. Freshwater Biology, 50, 1781-1785.

Fuller R.L., Fry T.J. \& Roelofs J.A. (1988) Influence of different food types on the growth of Simulium vittatum (Diptera) and Hydropsyche betteni (Trichoptera). Journal of the North American Benthological Society, 7, 197-204.

Gergs R. \& Rothhaupt K.O. (2008) Effects of zebra mussels on a native amphipod and the invasive Dikerogammarus villosus: the influence of biodeposition and structural complexity. Journal of the North American Benthological Society, 27, 541-548.

González M.J. \& Burkart G.A. (2004) Effects of food type, habitat, and fish predation on the relative abundance of two amphipod species, Gammarus fasciatus and Echinogammarus ischnus. Journal of Great Lakes Research, 30, 100-113.

Graca M.A.S., Cressa C., Gessner M.O., Feio M.J., Callies K.A. \& Barrios C. (2001) Food quality, feeding preferences, survival and growth of shredders from temperate and tropical streams. Freshwater Biology, 46, 947957.

Greenberg A.E., Trussel R.R. \& Clesceri L.S. (1985) Standard Methods for the Examination of Water and Wastewater. APHA, Washington D.C.

Izvekova E.I. \& Lvova-Katchanova A.A. (1972) Sedimentation of suspended matter by Dreissena polymorpha Pallas and its subsequent utilization by chironomidaelarvae. Polnisches Archiv für Hydrobiologie, 19, 203-210.

Kaushik N.K. \& Hynes H.B.N. (1971) The fate of the dead leaves that fall into streams. Archiv für Hydrobiologie, 68, 465-515.

Kelly D.W., Dick J.T.A. \& Montgomery W.I. (2002) Predation on mayfly nymph, Baetis rhodani, by native and introduced Gammarus: direct effects and the facilitation of predation by salmonids. Freshwater Biology, 47, 1257-1268.

Kinzler W. \& Maier G. (2006) Selective predation by fish: a further reason for the decline of native gammarids in the presence of invasives? Journal of Limnology, 65, 27-34.

Klerks P.L., Fraleigh P.C. \& Lawniczak J.E. (1996) Effects of zebra mussel (Dreissena polymorpha) on seston levels and sediment deposition in western Lake Erie. Canadian Journal of Fisheries and Aquatic Sciences, 53, 22842291.

Kolar C.S. \& Lodge D.M. (2001) Progress in invasion biology: predicting invaders. Trends in Ecology and Evolution, 16, 199-204.

Limén H., van Overdijk C.D.A. \& MacIsaac H.J. (2005) Food partitioning between amphipods Echinogammarus ischnus, Gammarus fasciatus, and Hyalella azteca as revealed by stable isotopes. Journal of Great Lakes Research, 31, 97-104.

MacNeil C., Dick J.T.A. \& Elwood R.W. (1997) The trophic ecology of freshwater Gammarus spp. (Crustacea: Amphipoda): problems and perspectives concerning 
the functional feeding group concept. Biological Reviews, 72, 349-364.

McCullough D.A. \& Minshall G.W. (1979) Bioenergetics of lotic filter-feeding insects Simulium spp. (Diptera) and Hydropsyche occidentalis (Trichoptera) and their function in controlling organic transport in streams. Ecology, 60, 585-596.

Minshall G.W. (1967) Role of allochthonous detritus in the trophic structure of a woodland springbrook community. Ecology, 48, 139-149.

Mitchell J., Mills E.L., Idrisi N. \& Michener R. (1996) Stable isotopes of nitrogen and carbon in an aquatic food web recently invaded by Dreissena polymorpha (Pallas). Canadian Journal of Fisheries and Aquatic Sciences, 53, 1445-1450.

Mörtl M. \& Rothhaupt K.O. (2003) Effects of adult Dreissena polymorpha on settling juveniles and associated macroinvertebrates. International Review of Hydrobiology, 88, 561-569.

Piscart C., Devin S., Beisel J.-N. \& Moreteau J.C. (2003) Growth-related life-history traits of an invasive gammarid species: evaluation with a Laird-Gompertz model. Canadian Journal of Zoology, 81, 2006-2014.

Pöckl M. (1992) Effects of temperature, age and body size at moulting and growth in the freshwater amphipoda Gammarus fossarum and G. roeseli. Freshwater Biology, 27, 211-225.

Pöckl M. (1995) Laboratory studies on growth, feeding, moulting and mortality in the freshwater amphipods Gammarus fossarum and G. roeseli. Archiv für Hydrobiologie, 134, 223-253.

Pöckl M. (2007) Strategies of a successful new invader in European freshwaters: fecundity and reproductive potential of the Potno-Caspian amphipod Dikerogammarus villosus in Austrian Danube, compared with the indigenous Gammarus fossarum and G. roeseli. Freshwater Biology, 52, 50-63.

Pyke D.A. \& Thompson J.N. (1986) Statistical analysis of survival and removal rate experiments. Ecology, 67, 240-245.

Ricciardi A. \& Rasmussen J.B. (1998) Predicting the identity and impact of future biological invaders: a priority for aquatic resource management. Canadian Journal of Fisheries and Aquatic Sciences, 55, 1759-1765.
Ricciardi A., Whoriskey F.G. \& Rasmussen J.B. (1997) The role of the zebra mussel (Dreissena polymorpha) in structuring macroinvertebrate communities on hard substrata. Canadian Journal of Fisheries and Aquatic Sciences, 54, 2596-2608.

Rothhaupt K.O. (1995) Algal nutrient limitation affects rotifer growth rate but not ingestion rate. Limnology and Oceanography, 40, 1201-1208.

Silver Botts P., Patterson B.A. \& Schloesser D.W. (1996) Zebra mussel effects on benthic invertebrates: physical or biotic? Journal of the North American Benthological Society, 15, 179-184.

Söderström O. (1988) Effects of temperature and food quality on life-history parameters in Parameletus chelifer and P. minor (Ephemeroptera): a laboratory study. Freshwater Biology, 20, 295-303.

Stanczykowska A., Lawacz W., Mattice J. \& Lewandowski K. (1976) Bivalves as a factor effecting circulation of matter in Lake Mikolajskie (Poland). Limnologica, 10, 347-352.

Sterner R.W. \& Elser J.J. (2002) Ecological Stoichiometry: The Biology of Elements From Molecules to the Biosphere. Princeton University Press, Princeton, NJ.

Stewart T.W. \& Haynes J.M. (1994) Benthic macroinvertebrate communities of southwestern Lake Ontario following invasion of Dreissena. Journal of Great Lakes Research, 20, 479-493.

Stewart T.W., Miner J.G. \& Lowe R.L. (1998) Quantifying mechanisms for zebra mussel effects on benthic macroinvertebrates: organic matter production and shellgenerated habitat. Journal of the North American Benthological Society, 17, 81-94.

Webster J.A. \& Benfield E.F. (1986) Vascular plant breakdown in freshwater ecosystems. Annual Review of Ecology and Systematics, 17, 567-594.

Willoughby L.G. \& Sutcliffe D.W. (1976) Experiments on feeding and growth of the amphipod Gammarus pulex (L.) related to its distribution in the River Duddon. Freshwater Biology, 6, 577-586. 